\title{
ANALISIS SIFAT MAGNETIK DAN STRUKTUR PARTIKEL PASIR BESI PANTAI ARTA PARIAMAN SUMATERA BARAT MENGGUNAKAN BALL MILLING
}

\author{
Wita Yulia ${ }^{1,}$, Erwin $^{2}$ \\ ${ }^{1}$ Mahasiswa Jurusan Fisika, Universitas Riau \\ ${ }^{2}$ Dosen Jurusan Fisika, Universitas Riau \\ *E-mail korespondensi: witayulia15@gmail.com
}

\begin{abstract}
Analisys of magnetic properties and structure of particles of iron sand of Arta, Pariaman beach West Sumatra. Has been conducted the iron sand samples were dried, then the iron sand separation process was carried out using Iron Sand Separator (ISS). Next, the sample was milled for 30, 60 and 90 hours. The separation between magnetic particles and non magnetic particles was done using Neodymium Iron Boron (NdFeB) magnet. Magnetic induction measurements were carried out using Pasco PS-2162 Magnetic Probe which measured the total magnetic induction of solenoid (solenoid with core sample and milled sample(consentrate II)) as a function of electric current of 1-8 A for a fixed distance of $1 \mathrm{~mm}$. Identification of the content of elements contained in iron sand before and after processing with Ball Milling for 90 hours was carried out using X-Ray Fluorescence (XRF). The phase of magnetic particles processed by Ball Milling was determined using X-Ray Diffraction (XRD). The calculation results show that the magnetic susceptibility of the sample increases with increasing Ball Milling time, from $\left(69426,19 \times 10^{-5}-80332,13 \times 10^{-5}\right)$. These values are in the interval $220-380.000 \times 10^{-5}$ of the Ilmenite mineral. The magnetite phase appears more than the maghemite phase and the hematite phase after Ball Milling for 90 hours. The particle size of magnetik particle decreases as milling time increase, this trend is confirmed by the result of XRD.
\end{abstract}

Keywords: Iron sand, Ball Milling, Mass susceptibility, X-Ray Diffraction (XRD)

\begin{abstract}
ABSTRAK
Telah dilakukan penelitian mengenai analisis sifat magnetik dan struktur partikel pasir besi pantai Arta Pariaman Sumatera Barat. Sampel pasir besi yang sudah diambil tersebut dikeringkan, kemudian dilakukan proses pemisahan pasir besi menggunakan Iron Sand Separator (ISS). Selanjutnya sampel di Ball Milling selama 30 jam, 60 jam dan 90 jam kemudian dilakukan pemisahan kembali menggunakan magnet Neodymium Iron Boron (NdFeB). Pengukuran induksi magnetik solenoida dilakukan menggunakan Probe Magnetic Pasco PS-2162 yang diukur nilai induksi magnetik total solenoid (solenoida dengan inti sampel dan konsentrat II) sebagai fungsi arus listrik untuk jarak yang tetap yaitu $1 \mathrm{~mm}$. Identifikasi kandungan elemen yang terdapat dalam pasir besi dan sesudah diproses dengan Ball Milling selama 90 jam dilakukan dengan menggunakan X-Ray Fluorescence (XRF). Fase dari partikel magnetik yang diproses Ball Milling ditentukan menggunakan X-Ray Diffraction (XRD). Hasil perhitungan menunjukkan bahwa nilai suseptibilitas magnetik bertambah seiring dengan bertambahnya waktu Ball Milling, dari $\left(69426,19 \times 10^{-5}-80332,13 \times 10^{-5}\right)$. Nilai ini berada dalam interval $220-380.000 \times 10^{-5}$ yang merupakan interval mineral Ilmenite. Fase magnetite muncul lebih banyak dibandingkan dengan fase maghemite dan fase hematite setelah di Ball Milling selama 90 jam. Partikel semakin kecil ukurannya dibuktikan dengan hasil XRD dengan bertambah lebarnya ukuran dari pola difraksi masing-masing puncak apabila proses Ball Milling lebih lama.
\end{abstract}

Kata kunci: Pasir besi, Ball Milling, Suseptibilitas massa, X-Ray Diffraction (XRD)

Diterima 18-07-2019| Disetujui 30-09-2019| Dipublikasi 31-10-2019 


\section{PENDAHULUAN}

Pasir besi merupakan bahan magnetik yang bersifat feromagnetik. Pasir besi memiliki komposisi yang terdiri dari fase magnetite $\left(\mathrm{Fe}_{3} \mathrm{O}_{4}\right)$ hematite $\left(\alpha-\mathrm{Fe}_{2} \mathrm{O}_{3}\right)$ dan maghemite $(\gamma-$ $\left.\mathrm{Fe}_{2} \mathrm{O}_{3}\right)$ [1]. Maghemit dan hematit, kedua bahan tersebut memiliki komposisi yang sama tetapi memiliki struktur kristal yang berbeda [2].

Pasir besi apabila disintesis hingga ukuran nanometer akan memiliki sifat superparamagnetik [3]. Sifat super-paramagnetik yang mana tidak akan ada pada bahan ukuran besar (bulk material). Super-paramagnetik bahan yang mempunyai magnetisasi saturasi tinggi dan koersivitas sangat kecil ketika bahan tersebut tidak dipengaruhi oleh medan magnet dari luar. Sifat-sifat ini muncul hanya saat bahan feromagnetik atau ferrimagnetik dalam ukuran yang sangat kecil (nanometer), sehingga fenomena ini telah menarik banyak peneliti menggunakan bahan ini dalam berbagai aplikasi, seperti pengiriman obat ke tempat tertentu didalam tubuh manusia dengan menggunakan medan magnet luar [4], pengobatan hipertermia, magnetik resonansi pencitraan [5], agen peningkatan, memanipulasi membran sel, biosensor, biolabel [6] dan adsorpsi ion logam [7]. Pasir besi juga merupakan bahan baku pembuatan baja yang banyak digunakan diberbagai bidang industri.

Metode yang digunakan untuk sintesis oksida besi yaitu metode fisika, kimia dan biologi [8]. Khususnya metode fisika yang digunakan metode Ball milling. Metode ini mengubah ukuran partikel magnetik hingga berukuran lebih kecil dengan mentransfer momentum pada bola-bola kecil yang berada di dalam tabung yang bergabung dengan sampel.

Penelitian ini akan dilakukan dimana pasir besi yang sudah dikeringkan akan dipisahkan menggunakan ISS (Iron Sand Separator) untuk memisahkan material magnetik dan nonmagnetik lalu digunakan metode milling untuk mendapatkan partikel ukuran kecil (nanomaterial) kemudian untuk menentukan struktur kristal dari partikel besi dikaraktarisasi menggunakan difraksi sinar-X (XRD).

\section{METODE PENELITIAN}

Penelitian ini menggunakan metode eksperimen yaitu untuk penggunaan metode ball milling untuk mendapatkan nanopartikel magnetik.

\section{Pengambilan Sampel}

Bahan atau sampel yang digunakan pada penelitian ini merupakan pasir pantai yang diambil langsung dari pantai Arta Pariaman Sumatera Barat dengan 5 lokasi berbeda yang terdiri dari titik A, B, C, D dan E. Tiap titik memiliki jarak sejauh $50 \mathrm{~m}$ masing-masing sampel dan $10 \mathrm{~m}$ dari bibir pantai yang diambil sebanyak $0,5 \mathrm{~kg}$. Cara pengambilan sampel dilakukan dengan menggunakan metode zig-zag.

\section{Proses Pengeringan dan Pemisahan Sampel}

Proses pengeringan sampel menggunakan sinar matahari, kemudian sampel ditimbang untuk mendapat nilai massanya dan diukur nilai $X_{m}$ dengan menggunakan Sensor Probe Pasco, selanjutnya pemisahan dilakukan dengan menggunakan Iron Sand Separator (ISS) di laboratorium Instrumentasi dan Kemagnetan Jurusan Fisika Universitas Riau dengan satu kali pemisahan.

\section{Pengukuran Induksi Magnetik}

Pengukuran induksi magnetik solenoid tanpa inti dan dengan inti dilakukan pada solenoid yang terbuat dari 2000 lilitan, panjang $10 \mathrm{~cm}$ dan diameter $3 \mathrm{~cm}$ yang terhubung dengan computer. Pengukuran tanpa inti diukur pada jarak antara ujung tengah solenoid dengan ujung sensor sejauh 1 mm dan arus yang diberikan yaitu 1, 2, 4, 6, 8 A, dan diukur pada arus yang konstan dan jarak yang bervariasi yaitu 1, 2, 3, 4, $5 \mathrm{~mm}$. 
Pengukuran induksi magnetik solenoid dengan inti dilakukan pada jarak antara ujung tengah solenoid dengan ujung sensor sejauh 1 $\mathrm{mm}$ dan arus yang diberikan yaitu 1, 2, 4, 6, 8 A.

\section{Metode Ball Milling}

Proses ball milling dalam penelitian ini diberikan perlakuan waktu yang berbeda yaitu 30 jam, 60 jam dan 90 jam yaitu gabungan sampel A, B, C, D dan E untuk mendapatkan konsentrat yang lebih kecil dan halus.

\section{Menentukan Suseptibilitas Magnetik}

Nilai suseptibilitas magnetik $\left(\chi_{m}\right)$ dapat ditentungan dengan cara nilai induksi magnetik pada konsentrat II pada proses ball milling $\left(\mathrm{B}_{\mathrm{T}}\right)$ dikurangi dengan induksi magnetik total yang tanpa inti $\left(\mathrm{B}_{0}\right)$, dan di bagi dengan nilia induksi magnetik total tanpa inti $\left(\mathrm{B}_{0}\right)$.

\section{Uji Kandungan Mineral Magnetik}

Sampel penelitian dibawa ke laboratorium Jurusan Fisika Fakultas Matematika dan Ilmu Pengetahuan Alam Universitas Andalas untuk diuji kandungan mineral magnetiknya menggunakan alat X-Ray Fluorescence (XRF). Sampel yang diuji ada 2 keadaan yaitu sampel pasir yang belum melalui proses pemisahan ISS kemudian pasir yang telah melalui proses pemisahan dan penghancuran dengan ball milling (konsentrat 2).

\section{Uji Difraksi Sinar-X}

Struktur dari sampel maka digunakan alat yaitu difraktometer sinar-x. Alat ini terdiri dari komponen utama yaitu sinar-x. Detektor sinar$\mathrm{x}$ dalam sistem penggerak sampel ketika sinar$\mathrm{x}$ ditembakkan ke arah sampel maka sinar-x dihamburkan ke arah detektor akan merekam sinar-x yang dihamburkan sebagai fungsi $2 \theta$.

\section{HASIL DAN PEMBAHASAN}

\section{Induksi Magnetik Solenoid Tanpa Inti}

Pengukuran induksi magnetik pada solenoid tanpa inti dengan arus konstan yaitu 8 A sebagai fungsi jarak terjadi perubahan pada nilai yang diperoleh. Nilai induksi magnetik pada jarak $1 \mathrm{~mm}$ dari solenoid dengan arus 8 A yaitu $8,069 \mathrm{mT}$. Nilai induksi magnetik diukur sebagai fungsi jarak yaitu $2 \mathrm{~mm}, 3 \mathrm{~mm}$, $4 \mathrm{~mm}, 5 \mathrm{~mm}$ adalah 7,933, 7,869, 7,683, 7,501 mT. Perubahan tersebut terjadi karena terjadi perubahan fluks magnetik di setiap jarak yang diberikan, semakin jauh dari solenoid maka fluks magnetik semakin tidak rapat sehingga mengakibatkan nilai induksi magnetik yang diperoleh berubah semakin kecil terlihat pada Gambar 1.

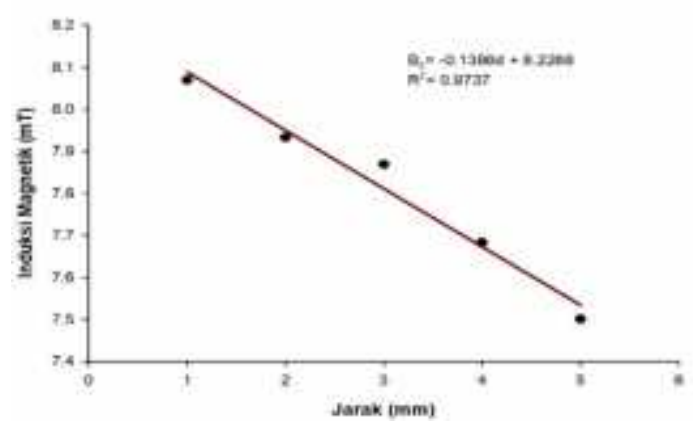

Gambar 1. Grafik hubungan jarak dengan induksi magnetik solenoid tanpa inti sebagai fungsi jarak arus tetap

Pengukuran induksi magnetik pada solenoid tanpa inti dengan arus konstan yaitu 8 A sebagai fungsi jarak terjadi perubahan pada nilai yang diperoleh. Nilai induksi magnetik pada jarak $1 \mathrm{~mm}$ dari solenoid dengan arus 8 A yaitu $8,069 \mathrm{mT}$. Nilai induksi magnetik diukur sebagai fungsi jarak yaitu $2 \mathrm{~mm}, 3 \mathrm{~mm}$, $4 \mathrm{~mm}, 5 \mathrm{~mm}$ adalah 7,933, 7,869, 7,683, 7,501 mT. Perubahan tersebut terjadi karena terjadi perubahan fluks magnetik di setiap jarak yang diberikan, semakin jauh dari solenoid maka fluks magnetik semakin tidak rapat sehingga mengakibatkan nilai induksi magnetik yang diperoleh berubah semakin kecil terlihat pada Gambar 1.

Pengukuran induksi magnetik menggunakan solenoid tanpa inti dengan jarak konstan $1 \mathrm{~mm}$ sebagai fungsi arus yaitu 1, 2, 4, 6, 8 A. Nilai induksi magnetik pada arus $1 \mathrm{~A}$ yaitu 1,069 nilai ini berubah semakin meningkat sesuai dengan bertambahnya arus yaitu berturut-turut dengan nilai 2,023, 4,083, 6,057, 8,069 mT. Perubahan nilai tersebut dapat dilihat dalam grafik pada Gambar 2. 
Perubahan nilai ini menunjukkan semakin meningkat arus semakin meningkat juga nilai induksi magnetik, nilai induksi magnetik sebanding dengan arus yang diberikan.

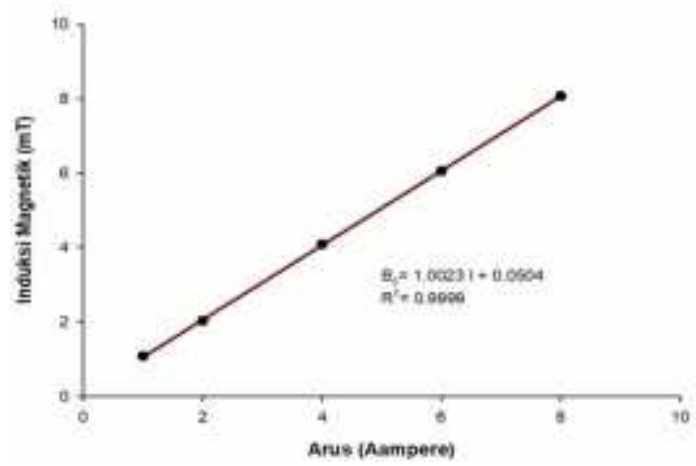

Gambar 2. Grafik hubungan arus dengan induksi magnetik solenoid sebagai fungsi arus jarak tetap $1 \mathrm{~mm}$.

\section{Suseptibilitas Magnetik}

Nilai suseptibilitas magnetik diperoleh setelah dilakukan pengukuran nilai induksi magnetik solenoid tanpa inti dan dengan inti.

\section{Suseptibilitas magnetik pasir besi}

Gambar 1 menunjukkan nilai suseptibilitas magnetik berada pada interval $458,54 \times 10^{-5}$ dan $1177,34 \times 10^{-5}$. Sifat magnetik dari sampel sebelum pemisahan termasuk dalam golongan sifat magnetik hematite (antiferromagnetik) yaitu dalam rentang 50$4000 \times 10^{-5}$ [9] nilai yang diperoleh masih kecil disebabkan karena pasir pantai masih banyak mengandung mineral non magnetik. Grafik nilai suseptibilitas magnetik pasir besi dari setiap titik lokasi dapat dilihat pada gambar berikut:

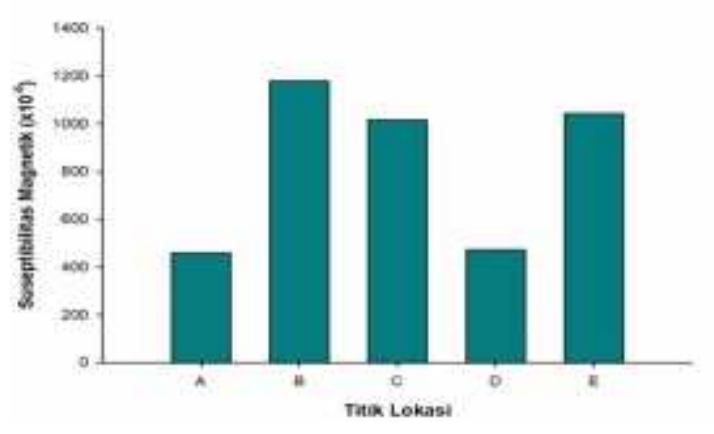

Gambar 3. Grafik nilai suseptbilitas magnetik pasir besi sebelum pemisahan setiap lokasi

Suseptibilitas Magnetik Konsentrat II
Gambar 4 menunjukkan nilai suseptibilitas magnetik pada waktu 90 jam Ball Milling dengan nilai $80332,13 \times 10^{-5}$, suseptibilitas magnetik pada waktu 60 jam dengan nilai $73751,39 \times 10^{-5}$ dan suseptibilitas magnetik pada waktu 30 jam dengan nilai $69426,19 \times$ $10^{-5}$. Nilai suseptibilitas magnetik pada konsentrat II dimasukkan kedalam golongan ilmenite (anti-ferromagnetik) dalam rentang $220-380.000 \times 10^{-5}[9]$.

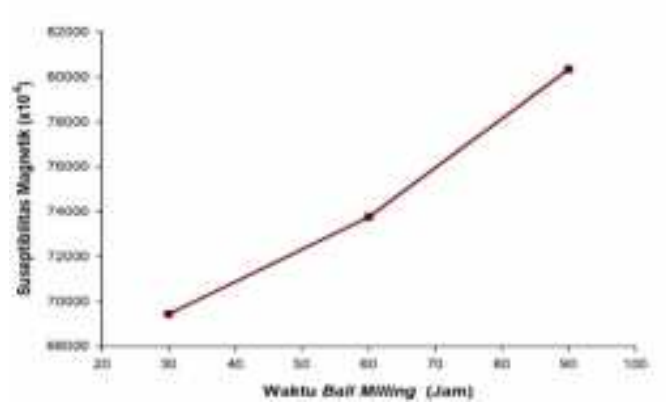

Gambar 4. Grafik hubungan nilai suseptibilitas magnetik setelah proses Ball Milling dan setelah dipisahkan menggunakan magnet dengan arus $8 \mathrm{~A}$.

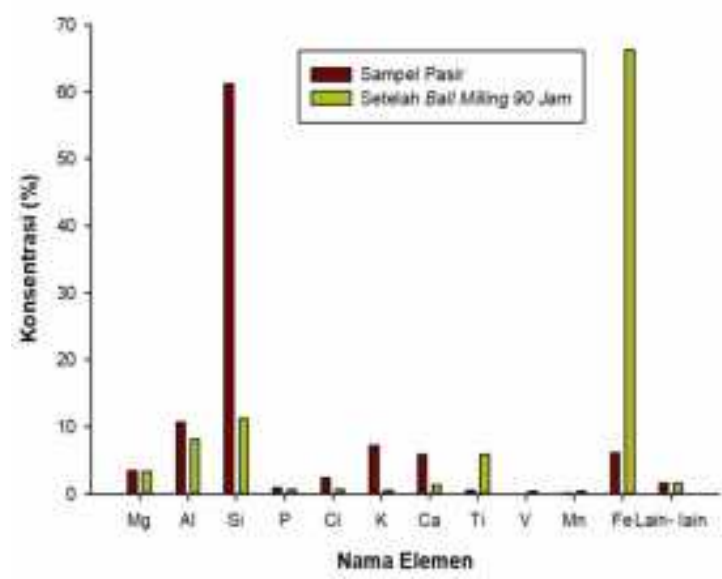

Gambar 5. Grafik perbandingan elemenelemen pasir besi dengan konsentrat II dari hasil XRF.

Nilai suseptibilitas magetik konsentrat II lebih tinggi dibandingkan dengan nilai suseptibilitas magnetik pasir besi, hal ini disebabkan karena konsentrat II sudah melalui dua tahapan proses yaitu pemisahan menggunakan ISS dan Ball Milling dengan variasi waktu 30, 60 dan 90 jam kemudian dipisahkan kembali menggunakan magnet 
permanen sehingga memiliki konsentrasi mineral magnetik yang jauh lebih tinggi seperti ditampilkan hasil XRF pada Gambar 5.

\section{Data Hasil X-Ray Fluorescence (XRF)}

Identifikasi yang dilakukan untuk mengetahui komposisi dari pasir besi yaitu dengan menggunakan XRF di Pantai Arta Pariaman Sumatera Barat. Hasil identifikasi kandungan elemen-elemen yang diperoleh dari hasil pengukuran sampel.

Gambar 5 menunjukkan perbedaaan komposisi yaitu adanya penambahan dan pengurangan dari elemen - elemen tertentu. Komposisi dari konssentrat dipengaruhi oleh waktu Ball Milling. Grafik tersebut menunjukkan bahwa kandung Fe meningkat sangat signifikan setelah dilakukan proses Ball Milling namun untuk beberapa unsur mengalami penurunan seperti $\mathrm{Si}, \mathrm{K}, \mathrm{Ca}$, kemudian untuk unsur lain seperti $\mathrm{Ti}, \mathrm{V}$ dan Mn meningkat. Ini menunjukkan bahwa proses penggilingan pada bola didalam tabung Ball Milling memecah butiran pasir besi menjadi bagian-bagian yang lebih kecil sehingga butiran non-magnetik dan magnetik dipisahkan selama proses penggilingan terjadi. Selain itu, pada Fe dan Si terjadi perbedaan komposisi setelah terjadinya Ball Milling hal ini dapat disimpulkan bahwa proses Ball Milling mampu menghancurkan sampel sehingga terpisah partikel magnetik dari non magnetik. Grafik ini menunjukkan bahwa pengaruh induksi dari sampel dan konsentrat II untuk 90 jam terjadi peningkatan dapat dikatakan karena meningkatnya kadar $\mathrm{Fe}$ menjadi $66,23 \%$ dan berkurangnya unsur-unsur non magnetik.

\section{Data Hasil Difraksi Sinar-X (XRD)}

Karakterisasi fase partikel magnetik dari pasir besi yang sudah diproses dengan Ball Milling menggunakan difraksi sinar-x (XRD). Fase magnetik untuk pasir besi yang diproses dengan Ball Milling 90 jam penggilingan. Partikel dari oksida besi dikarakterisasi menggunakan X-Ray Diffractometer dengan tabung $\mathrm{Cu}$ yang sinar-X dengan panjang gelombang 1,5406 Angstrom. Tabung $\mathrm{Cu}$ eksperimen ini digunakan sumber tegangan sekitar $40 \mathrm{kV}$ dan arus $30 \mathrm{~mA}$. Pola difraksi sinar-x dari pasir besi yang disintesis setelah 90 jam waktu Ball Milling pada gambar berikut:

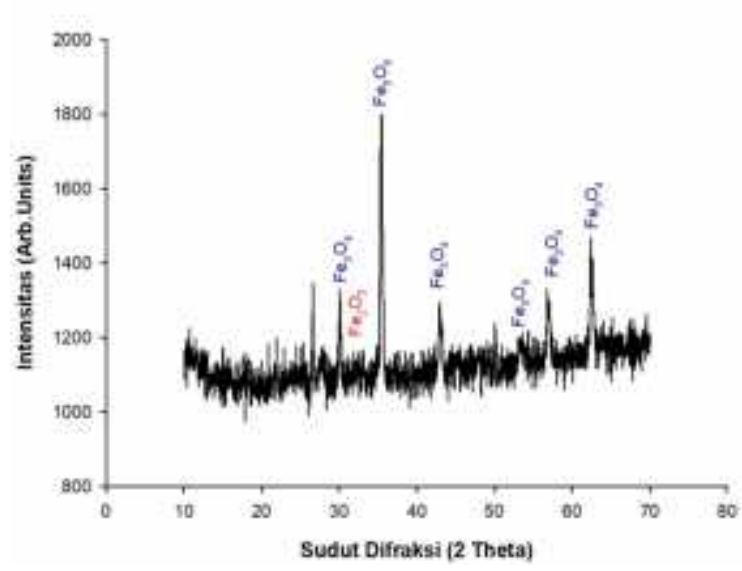

Gambar 6. Pola difraksi sinar-x pada

konsentrat setelah Ball Milling selama 90 jam.

Gambar 6. menunjukkan dua pola XRD untuk pasir besi yang diproses dengan Ball Milling 90 jam. Hasil dari XRD dapat dilihat bahwa puncak difraksi pada sampel setelah penghancuran 90 jam pada nilai $2 \theta$ yaitu $30,04^{\circ}, 32,47^{\circ}, 35,47^{\circ}, 43,00^{\circ}, 53,45^{\circ}, 57,02^{\circ}$ dan $62,70^{\circ}$ sepenuhnya cocok dengan bidang (220), (311), (400), (422), (511), (440).

Pola difraksi semakin melebar ketika ukuran partikel berkurang dengan meningkatnya waktu Ball Milling seperti yang ditunjukkan pada Gambar 6. Fase magnetite pada pasir besi setelah melalui proses Ball Milling 90 lebih banyak dibandingkan dengan fase pada 30 jam hal ini disebabkan karena pengaruh Ball Milling pada sampel 90 jam memiliki ukuran partikel yang lebih kecil dibandingkan dengan ukuran partikel yang 30 jam. Perbedaan ukuran ini dapat dilihat dari nilai lebar dari setengah puncak (FWHM) yang diperoleh dari sampel 90 jam karena besar nilai FWHM berbanding terbalik dengan ukuran partikel magnetik sesuai dari persamaan Scherrer.

\section{KESIMPULAN}


Proses Ball Milling telah berhasil memisahkan sebagian besar partikel non magnetik dengan partikel magnetik dengan menggunakan waktu maksimum 90 jam. Fase magnetite muncul lebih banyak dibandingkan dengan fase maghemite dan fase hematite setelah di Ball Milling selama 90 jam. Partikel semakin kecil ukurannya dibuktikan dengan hasil XRD dengan bertambah lebarnya ukuran dari pola difraksi untuk 90 jam Ball Milling. Komposisi dari konsentrat menunjukkan bahwa kandungan $\mathrm{Fe}$ meningkat $66,23 \%$ setelah proses Ball Milling selama 90 jam dibandingkan dengan 30 jam, Namun beberapa elemen lain untuk $\mathrm{Si}, \mathrm{Al}, \mathrm{K}$, dan $\mathrm{Ca}$ mengalami penurunan. Nilai suseptibilitas magnetik pasir besi pantai Arta Pariaman Sumatera Barat yang telah diproses dengan Ball Milling selama 90 jam berada dalam interval (220-380.000) × $10^{-5}$ yang merupakan interval mineral Ilmenite (antiferromagnetik) yaitu sebesar $80332,13 \times 10^{-5}$.

\section{REFERENSI}

1. Kurniawan,C., AS, Eko., YS, Ayu., Shite, PTA., Ginting, M., Simamora,P dan Sebayang,P. 2017. Synthesis and Characterization of Magnetic Elastomer Based PEG- Coated $\mathrm{Fe}_{3} \mathrm{O}_{4}$ From Natural Iron Sand. Materials Science and Engineering. $202,1-7$

2. Dunlop, D.J and O, Ozdemir. 1997. Rock Magneism: Fundamental and Frontiers.
Cambridge University Press. Vol.135 .278- 300 .

3. Setiadi,E.A, P. Sebayang, M. Ginting, A.Y.Sari, C. Kusniawan, C.S. Saragih dan P. Simamora. 2016. The Synthesization of $\mathrm{Fe}_{3} \mathrm{O}_{4}$ Magnetic Nanoparticles Baesed on Natural Iron Sand By Co-Presipitation Method The Adsorbtion of $\mathrm{Cu}$ and $\mathrm{Pb}$ Ions. Journal of Physics . 776. 1-6.

4. Arias,J.L., Gallardo,V., Ruiz,M.A., Delgado,A.V. 2008. Magnetite/ poly (alkylcyanoacrylate)( core/shell) nanoparticles as 5-Fluouracil delivery systems for active targeting. 2008. Eur.J.Pharm. Biopharm. Vol,69, 54-63

5. Feng B, Hong R Y, Wang L S, Guo L, Li H Z Ding J Zheng Y and Wei D G. 2008. Colloids Surfaces A Physicochem. Eng. Asp. 32852

6. Anbarasu M, Anandan M, Chinnasamy E, Gopinath V and Balamurugan K2015 Spectrochim.ACTA Part A Mol. Biomol. Spectrosc. 135536

7. Larraza I,. López-gónzalez M,. Corrales T,. and Marcelo G,. 2012 J. Colloid Interface Sci. 38524

8. Dave, Paragnesh. N and Chopda, Lakhan.V .2014. Aplicatio of Iron Oxide Nanomaterial for The Removal of Heavy Metals, Journal of Nnanotechnology. ID.398569

9. Hunt, C.P., Moskowitz, B.M., Banerjee, S.K. 1995. Magnetic Properties of Rokcs and Minerals. 